\title{
A WIRELESSLY-ACTIVATED PARYLENE ELECTROTHERMAL VALVE FOR MAPPING BRAIN FUNCTION IN FREELY MOVING SUBJECTS
}

Po-Ying Li ${ }^{1}$, Tina K. Givrad ${ }^{2}$, Daniel P. Holschneider ${ }^{2,3}$, Jean-Michel I. Maarek ${ }^{2}$, and Ellis Meng ${ }^{2}$

${ }^{1}$ Department of Electrical Engineering, University of Southern California, Los Angeles, California, USA

${ }^{2}$ Department of Biomedical Engineering, University of Southern California, Los Angeles, California, USA

${ }^{3}$ Department of Psychiatry, Neurology, Cell and Neurobiology, University of Southern California, Los Angeles, California, USA

\section{ABSTRACT}

The first normally-closed Parylene valve operating on electrothermal principles for rapid and wireless drug delivery was designed, fabricated, modeled, and tested. This valve is a key component of an implantable microbolus infusion pump (MIP) for neuroimaging in freely-moving untethered animals. This low-power, lightweight MEMS valve enables an MIP suitable for studying functional brain activation in genetically engineered mice by replacing a large conventional solenoid valve used previously in larger animals.

\section{INTRODUCTION}

In traditional neuroimaging, to avoid movement artifacts during data acquisition, subjects need to be immobilized or anesthetized. This is one of the major constraints on neuroimaging in animals which prevents study of fundamental behaviors linked to locomotor activities and introduces additional variables of stress or anesthetic agent that may confound meaningful interpretation. To acquire detailed understanding of the neural mechanisms underlying fundamental mammalian behaviors, such as aggression, mating, feeding, and fear, new techniques are required.

An implantable microbolus infusion pump (MIP) (Fig. 1) consisting of a drug reservoir, tuned inductive coil, catheter, and valve has been introduced for drug delivery in rats [1,2]. The MIP has allowed, for the first time, cerebral perfusion mapping in conscious freely-moving small animals. The remotely triggered valve initiates rapid release of a radioactive tracer from a pressurized reservoir directly into systemic circulation followed by rapid euthanasia. Regional cerebral blood flow is assessed using autoradiography. However, to apply the same drug delivery scheme to smaller animals, such as mice, a key requirement of the MIP system is the total weight and size of the implant which must be less than 3 grams and allow for subcutaneous implantation in a 40-gram mouse. In addition, the valve footprint should match the inner diameter of the catheter (330 or $500 \mu \mathrm{m}$ ). Current technology in implantable drug delivery in small animals (constant rate infusion pump) is unable to achieve the rapid injection necessary to prevent nonspecific tracer distribution. A new valve is required that reduces the overall weight and size of the MIP (from $32 \mathrm{~g}$ to $<3 \mathrm{~g}$ total weight) for implantation in genetically engineered mice ( $\sim 40 \mathrm{~g})$ and maintains the ability to open quickly for on-demand release of a radiotracer.
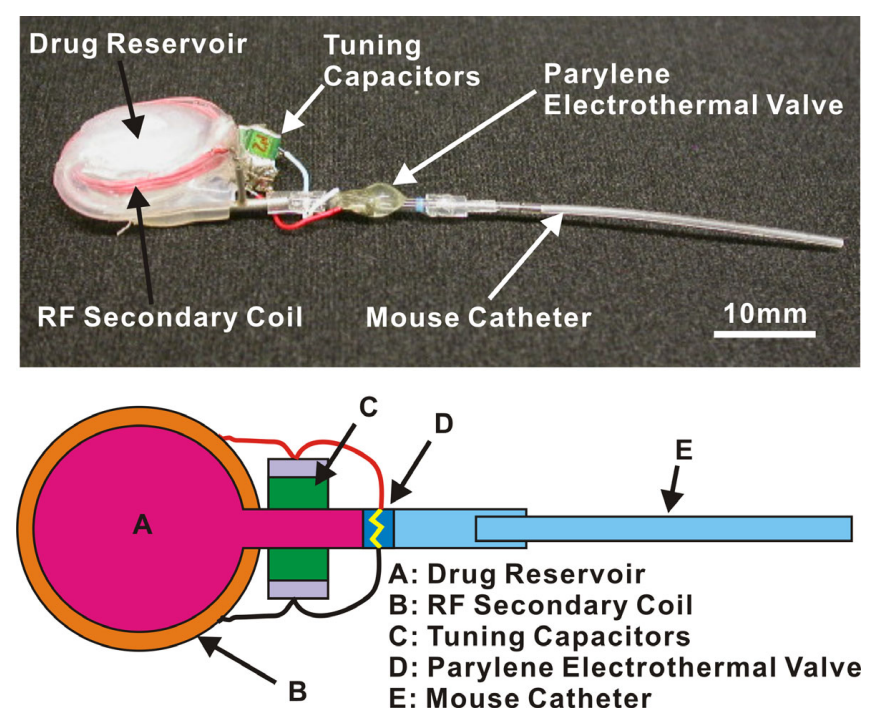

Figure 1: Miniature bolus infusion pump for neuroimaging in mice.

Normally-closed MEMS electrothermal valves capable of rapid opening provide a potential solution for the new MIP system. Previously, electrothermal valves have been developed but only one of these is suited for implantable drug delivery (Table 1) [3-8]. This valve consists of a resistive metallic membrane $(\mathrm{Pt} / \mathrm{Ti} / \mathrm{Pt})$ suspended over a drug reservoir that opens when an applied current melts the membrane. However, melting the metallic membranes requires significant power to produce the necessary temperature. Here, we use a Parylene C/Pt composite membrane since Parylene $\mathrm{C}$ can be thermally degraded at much lower temperature $\left(125-200^{\circ} \mathrm{C}\right)$ [9] and can form large mechanically robust membranes for larger effective valve opening area (330-500 $\mu \mathrm{m}$ in diameter).

Table 1: Comparison of the our valve with valves reported in research literature.

\begin{tabular}{|c|c|c|c|c|c|c|c|}
\hline & Maloney [3] & Cardenas-Valencia [4] & Mueller [5] & Hong [6] & Guerin [7] & McDonald [8] & Our Device \\
\hline Membrane Materials & $\mathrm{Pt} / \mathrm{Ti} / \mathrm{Pt}$ & $\mathrm{SiN}_{\mathrm{x}}$ & Doped Silicon & Un-crosslinked SU-8 & PE/PET Film & PDMS & Parylene \\
\hline $\begin{array}{c}\text { Membrane Dimension } \\
\mathrm{L} \text { x W x T }(\mu \mathrm{m})\end{array}$ & $50 \times 50 \times 0.01$ & $3000 \times 3000 \times 3$ & N/A x N/A x 50 & N/A x N/A x 50 & N/A x N/A x 35 & $100 \times 60 \times 20$ & $ø 500 \times 10$ (thick) \\
\hline Thermal Element Materials & $\mathrm{Pt} / \mathrm{Ti} / \mathrm{Pt}$ & $\mathrm{Pt} / \mathrm{Ti}$ & Doped Si & $\mathrm{Ni}$ & $\mathrm{Cu}$ & $\mathrm{Pt}$ & $\mathrm{Pt}$ \\
\hline Thermal Element Thickness $(\AA)$ & $10 / 100 / 10$ & $300 / 90$ & 500000 & 50000 & N/A & N/A & 1000 \\
\hline Mass Transport Mechanism & Diffusion & Pressure Driven & Pressure Driven & Pressure Driven & Pressure Driven & Pressure Driven & Pressure Driven \\
\hline Max. Pressure (kPa (psi)) & N/A & $500.0(72.5)$ & $20684.3(3000)$ & $96.5(14)$ & $200.0(29)$ & N/A & $689.4(100)$ \\
\hline Melting Temperature $\left({ }^{\circ} \mathrm{C}\right)$ & 1770 & 700 & 1400 & 50 & 120 & $\mathrm{~N} / \mathrm{A}$ & 125 \\
\hline Opening Power $(\mathrm{mW})$ & 2250 & 16000 & 300 & 0.08 & 400 & 7.5 & 25.2 \\
\hline Applied Voltage (V) & N/A & 70 & N/A & 0.7 & 1.5 & 420 & 3.6 \\
\hline Applied Current (mA) & 1000 & $\mathrm{~N} / \mathrm{A}$ & N/A & $\mathrm{N} / \mathrm{A}$ & N/A & $\mathrm{N} / \mathrm{A}$ & 7 \\
\hline Opening Time (ms) & 0.01 & 20 & 0.1 & 1000 & 1200 & 0.02 & 100 \\
\hline Energy $(\mathrm{mJ})$ & 0.025 & 320 & 30 & 0.08 & 400 & 150 & 2.52 \\
\hline Biocompatibility & Yes & No & No & No & No & No & Yes \\
\hline $\begin{array}{l}\text { Delivered Material } \\
\text { (Solid/Liquid/Gas) }\end{array}$ & Solid/Liquid & Liquid & Gas & Gas & Liquid & Liquid & Liquid \\
\hline
\end{tabular}


Table 2: Valve design parameters.

\begin{tabular}{cccc}
\hline Valve ID & $\mathbf{3 3 0 2 0}$ & $\mathbf{5 0 0 2 0}$ & $\mathbf{5 0 0 4 0}$ \\
\hline Layout & & & \\
& & & \\
\hline Occupied Diameter $(\mu \mathrm{m})$ & 330 & 500 & 500 \\
\hline Element Line Width $(\mu \mathrm{m})$ & 20 & 20 & 40 \\
\hline Total Element Length $(\mu \mathrm{m})$ & 1780 & 3880 & 2380 \\
\hline
\end{tabular}

\section{DESIGN}

The electrothermal drug delivery valve consists of an electron-beam evaporated platinum thin film platinum resistive element embedded in a flexible Parylene C membrane $(10 \mu \mathrm{m})$ (Fig. 2 and Table 2). Parylene further simplifies the valve design by obviating the etched silicon membrane support. The valve is situated in the lumen of a catheter and two contact pad flaps are wrapped along the catheter for connection to control circuitry (Fig. 2c). Current is applied to initiate Joule heating to thermally degrade or melt the Parylene membrane. When the electrical and mechanical connections are broken, the pressurized reservoir drives rapid release of fluids through the catheter and into the venous circulation. This convenient format can be implemented in many microfluidic applications where an inexpensive, disposable valve is required.

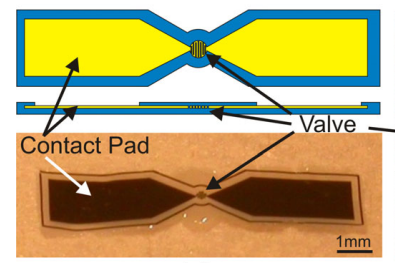

(a)

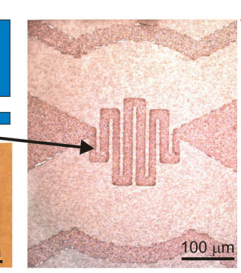

(b)

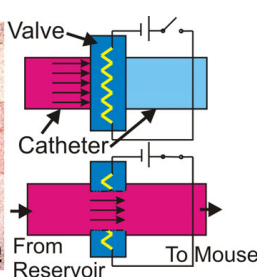

(c)
Figure 2: Parylene electrothermal drug delivery valve: (a) device layout, (b) close-up of valve element, and (c) illustration of operation principle of the valve.

\section{Modeling}

To ensure that the Pt element can survive the instantaneous peak pressure from reservoir (1 atm), membrane mechanical performance was verified using both large deflection approximation (Parylene only) and nonlinear FEM models (Parylene/Pt/Parylene). First, in the large deflection theory [10], the nonlinear strain-displacement relations can be expressed as

$$
\begin{aligned}
& \varepsilon_{x}=\frac{\partial u}{\partial x}+\frac{1}{2}\left(\frac{\partial w}{\partial x}\right)^{2} \\
& \varepsilon_{y}=\frac{\partial v}{\partial y}+\frac{1}{2}\left(\frac{\partial w}{\partial y}\right)^{2} \\
& \gamma_{z}=\frac{\partial v}{\partial x}+\frac{\partial u}{\partial y}+\frac{\partial w}{\partial x} \frac{\partial w}{\partial y}
\end{aligned}
$$

where $\varepsilon_{x}, \varepsilon_{y}$, and $\varepsilon_{z}$ and $u, v$, and $w$ are stresses and displacements in $x, y$ and $z$ directions, respectively. The corresponding governing differential equations are

$$
\begin{aligned}
& \frac{\partial^{4} \phi}{\partial x^{4}}+2 \frac{\partial^{4} \phi}{\partial x^{2} \partial y^{2}}+\frac{\partial^{4} \phi}{\partial y^{4}}=E\left[\left(\frac{\partial^{2} w}{\partial x \partial y}\right)^{2}-\frac{\partial^{2} w}{\partial x^{2}} \frac{\partial^{2} w}{\partial y^{2}}\right] \text { and } \\
& \frac{\partial^{4} w}{\partial x^{4}}+2 \frac{\partial^{4} w}{\partial x^{2} \partial y^{2}}+\frac{\partial^{4} w}{\partial y^{4}}=\frac{t}{D}\left[\frac{p}{t}+\frac{\partial^{2} \phi}{\partial y^{2}} \frac{\partial^{2} w}{\partial x^{2}}+\frac{\partial^{2} \phi}{\partial x^{2}} \frac{\partial^{2} w}{\partial y^{2}}-2 \frac{\partial^{2} \phi}{\partial x \partial y} \frac{\partial^{2} w}{\partial x \partial y}\right]
\end{aligned}
$$

where $\phi$ is the stress function, $E$ is Young's modulus, $t$ is the thickness of the plate, $D$ is the flexural rigidity, and $p$ is the applied pressure. By using the minimum strain energy method, the solution for a clamped thin circular plate subject to a uniform load $p_{0}$ is

$$
\frac{p_{0} a^{4}}{64 D}=0.488\left(\frac{w_{\max }}{t}\right)^{3}
$$

Nonlinear FEM analysis was also performed (Fig. 3). The results indicated that the maximum stress of the Pt element under $1 \mathrm{~atm}$ pressure (peak under normal operation) is 1.53GPa which is less than its tensile strength $(1.83 \mathrm{GPa})$. Thus, the electrical connections are expected to survive pressurized conditions during radiotracer loading. The nonlinear model results showed good agreement with load deflection experiments (composite membrane) obtained using a custom pressure testing setup (Fig. 4).

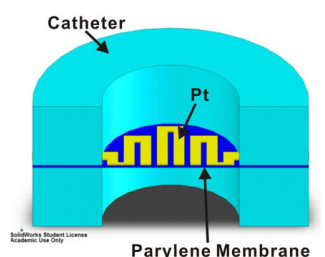

(a)

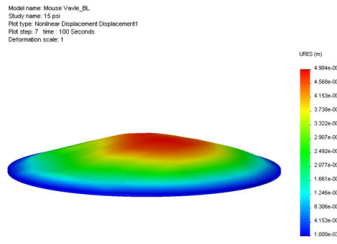

(c)

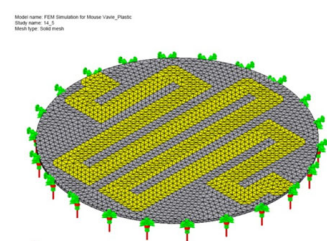

(b)

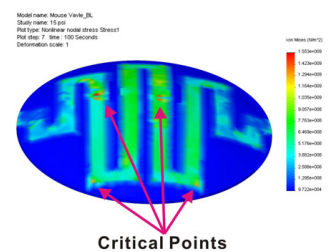

(d)
Figure 3: Finite element analysis using COSMOSWorks ${ }^{\circledR}$ : (a) nonlinear FEM model, (b) mesh, (c) vertical displacement (1 atm), and (d) stress distribution (1 atm).

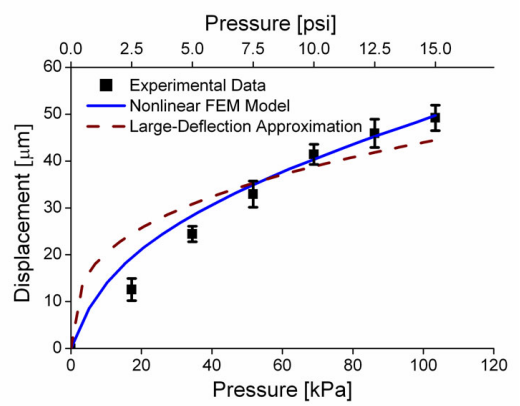

Figure 4: Comparison of experimental data with nonlinear FEM model and large-deflection approximation.

\section{FABRICATION}

The valves were constructed using standard microfabrication techniques. The fabrication began with a 3 inch Si wafer with native oxide to facilitate Parylene $C$ release. First, Parylene layer (5 $\mu \mathrm{m}$ thick) was deposited (Fig. 5A). This is the first layer of the Parylene/metal/Parylene sandwich. Two layers of photoresist (AZ1518 and AZ4400) were spun to create an undercut for Pt liftoff (Fig. 5B). Then liftoff lithography was performed and a $1000 \AA \mathrm{Pt}$ film was e-beam evaporated. Following liftoff, the resistive element and contact pad were defined (Fig. 5C). The top Parylene layer (5 $\mu \mathrm{m}$ thick) was then deposited (Fig. 5D). To reveal the contact pad openings, a thick photoresist layer (8 $\mu \mathrm{m}$ of AZ4400) was patterned as a mask for reactive ion etching (Fig. 5E). The Parylene over the contacts was removed by oxygen plasma. Then the photoresist was stripped and thermally annealed in vacuum with nitrogen backfill $\left(200^{\circ} \mathrm{C}\right.$ for 2 days) (Fig. 5F). The entire wafer was immersed into DI water to release the valves and the individual devices were manually cut from the wafer (Fig. 5G). 


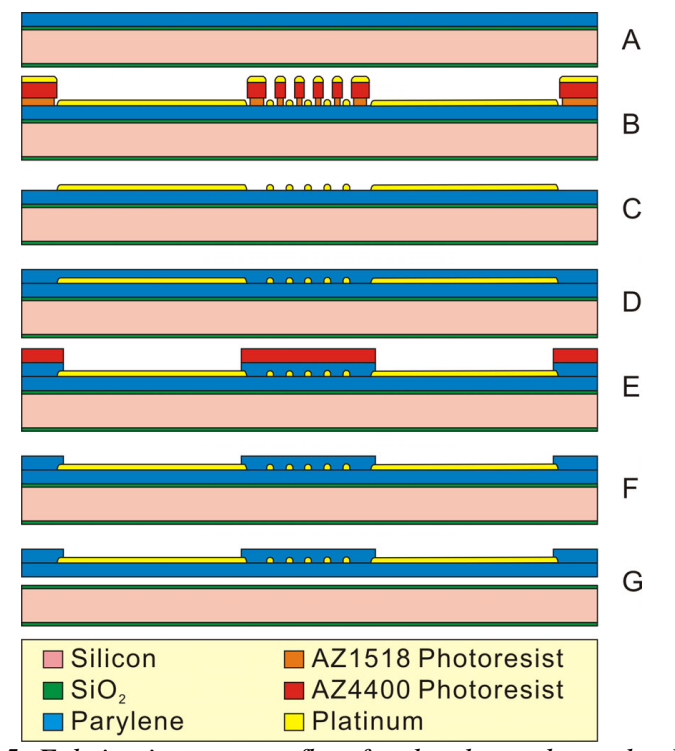

Figure 5: Fabrication process flow for the electrothermal valve.

\section{Valve Assembly}

The valve is situated in the lumen of a catheter and two contact pad flaps are wrapped along the catheter for connection to control circuitry (Fig. 6). To package the valve, the device was first sandwiched between two catheter segments and two laser-cut double-sided adhesive rings (Fig. 6a). Then conductive epoxy was used to secure electrical wires to the contact pads $\left(150^{\circ} \mathrm{C}\right.$ for 15 hours) (Fig. 6b and d). Finally, the joined assembly was strengthened with a bead of epoxy (Fig. 6c and e). The assembly process was performed under a stereo microscope.

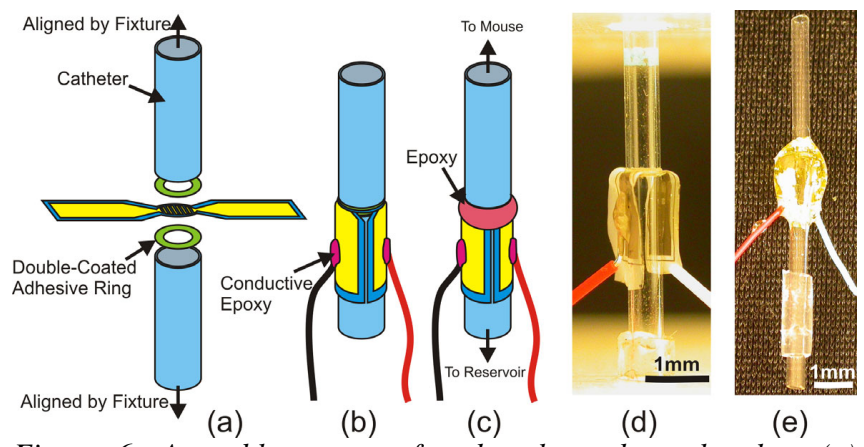

Figure 6: Assembly process for the electrothermal valve: (a) exploded view of components, (b) conductive epoxy for wire attachment, (c) epoxy bonding of the assembly, (d) wires attached to the contact pad by conductive epoxy, and (e) packaged device.

\section{EXPERIMENTAL METHOD}

\section{Benchtop Testing}

The temperature coefficient of resistivity (TCR), overheat temperature (OHT), and valve opening power of the Parylene $\mathrm{C}$ electrothermal valve were determined in benchtop experiments. TCR is an important parameter to predict Pt heater resistance at different temperatures. The temperature dependence of $\mathrm{Pt}$ is approximately linear over the range of interest and can be express as

$$
R(T)=R\left(T_{0}\right)\left[1+\alpha\left(T-T_{0}\right)\right]
$$

where $R(T)$ is the resistance at temperature $T, T_{o}$ is an appropriate reference temperature, and $\alpha$ is the TCR. In addition, the OHT allows the temperature of the resistive element to be calculated from its resistance. Pt element resistances for different applied currents were obtained. Then the valve element temperature can be estimated by using the following equation and the experimentally determined TCR:

$$
T=T_{0}+\frac{R(T)-R\left(T_{0}\right)}{\alpha R\left(T_{0}\right)}
$$

The valve opening experiments were performed in both air and water. In air, the valve opening power and current were obtained by applying constant current starting from $1 \mathrm{~mA}$ and increasing in small increments; the current corresponding to valve opening was recorded. Corresponding opening power values were calculated. Current ramping was also examined for valve operation in water. Five ramping rates were tested to obtain reliable valve opening. The devices were evaluated by using a laser-machined test fixture to allow rapid electrical connections and facilitate visual observation of the valve. The entire process was monitored by a compound microscope connected to a computer-controlled CCD camera capable of recording time lapse images.

\section{RESULTS AND DISCUSSION}

TCR calibration experiment results are presented in Fig. 7a. A typical TCR for our e-beam deposited thin film Pt heater was $16.3 \mathrm{x}$ $10-4 /{ }^{\circ} \mathrm{K}$ which is lower than that expected for bulk Pt TCR $(39.2 \mathrm{x}$ $\left.10-4 /{ }^{\circ} \mathrm{K}\right)$. This TCR value was applied to the OHT measurements to predict the Pt heater temperature at different applied currents (Fig. 4b). To prevent destructive thermal degradation of the device under test, the OHT experiments were performed at currents below opening values and the results were extrapolated to higher current ranges by using a 2nd-order polynomial curve fit. As depicted in Fig. 4b, a valve opening current between 10 to $15 \mathrm{~mA}$ was expected.

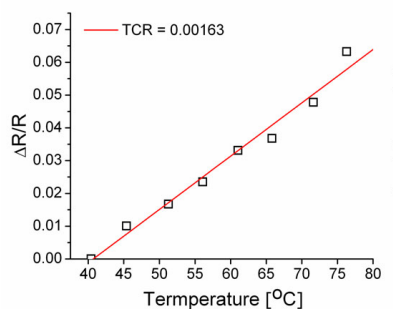

(a)

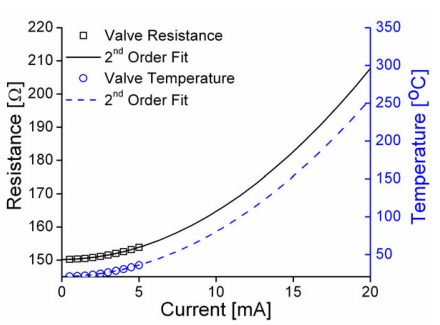

(b)
Figure 7: Representative valve electrothermal calibration curves (a) temperature dependence and (b) overheat temperature.

Valves were successfully opened in air (constant current) and water (current ramping) (Fig. 8-10). For constant current, opening current and power decreased with increasing resistance. The stages of valve opening (in water) were observed in real-time while simultaneously tracking the resistance by using current ramping. Five ramping rates $(0.025$ to $2 \mathrm{~mA} / \mathrm{sec})$ were tested to obtain the optimal opening rate (Table 3 ). Reliable valve opening was obtained for ramping rates less than $0.1 \mathrm{~mA} / \mathrm{sec}$.

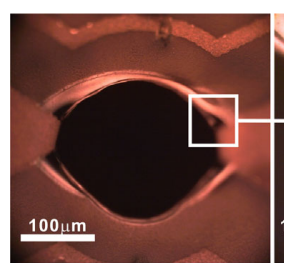

(a)

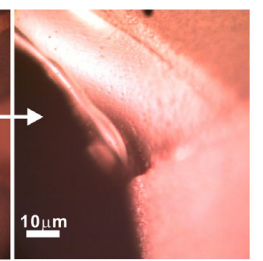

(b)

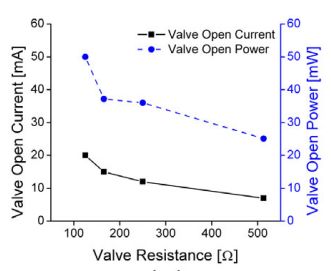

(c)
Figure 8: Valve opening (in air): (a) an open valve (15 mA), (b) magnified view of the edge of the valve orifice, and (c) valve opening current and power to resistance relationship. 

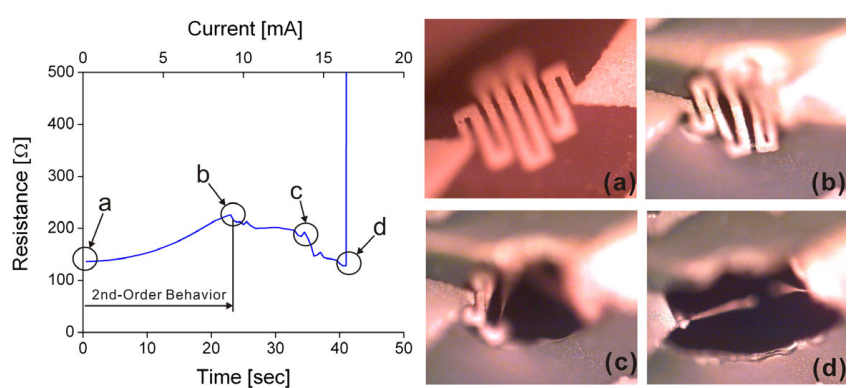

Figure 9: Valve opening (in water). Left: real-time response of the valve. Right: (a-d) time lapse images of valve opening corresponding to resistance measurement events in the left plot.

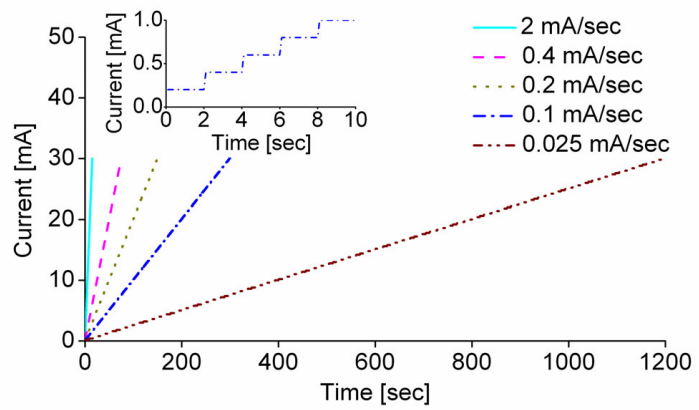

Figure 10: Current ramping rate. The inset shows a close up of the $0.1 \mathrm{~mA} / \mathrm{sec}$ waveform.

Table 3: Optimization results for current ramping testing in water.

\begin{tabular}{ccccccc}
\hline $\begin{array}{c}\text { Ramping } \\
\text { Rate } \\
(\mathrm{mA} / \mathrm{sec})\end{array}$ & \multicolumn{2}{c}{ Valve ID 33020 } & \multicolumn{2}{c}{ Valve ID 50020 } & \multicolumn{2}{c}{ Valve ID 50040 } \\
\cline { 2 - 7 } & Open & $\begin{array}{c}\text { Not } \\
\text { Open }\end{array}$ & Open & $\begin{array}{c}\text { Not } \\
\text { Open }\end{array}$ & Open & $\begin{array}{c}\text { Not } \\
\text { Open }\end{array}$ \\
\hline 0.025 & $\mathrm{O}$ & & $\mathrm{O}$ & & $\mathrm{O}$ & \\
\hline 0.1 & $\mathrm{O}$ & & $\mathrm{O}$ & & $\mathrm{O}$ & \\
\hline 0.2 & & $\mathrm{X}$ & & $\mathrm{X}$ & $\mathrm{O}$ & \\
\hline 0.4 & $\mathrm{O}$ & & & $\mathrm{X}$ & & $\mathrm{X}$ \\
\hline 2.0 & & $\mathrm{X}$ & $\mathrm{X}$ & & $\mathrm{X}$ \\
\hline
\end{tabular}

\section{NEUROIMAGING}

Valve integration into the new MIP design has commenced and wireless operation has already been demonstrated in the mouse emitter coil cage (Fig. 11a). Neuroimaging studies are planned and autoradiographic brain slices and optical density analysis will be obtained. Fig. 11b compares the dimensions of the MIP and a mouse.

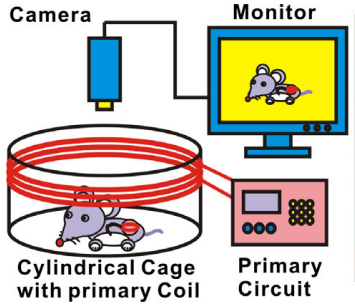

(a)

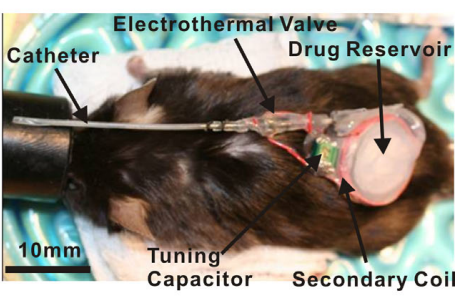

(b)
Figure 11: Neuroimaging: (a) in vivo testing setup in which the MIP is powered by inductive power transfer from a primary coil wrapped around the experimental cage, (b) relative size of the MIP and a mouse.

\section{CONCLUSION}

We successfully developed a disposable, low-power Parylene C MEMS valve for neuroimaging applications. The design, modeling, fabrication, and benchtop characterization were performed and investigated. TCR and OHT experiments allowed prediction of the temperature of the heater and determination of the appropriate current to apply to open the valve. Opening powers of 25-50 $\mathrm{mW}$ were obtained in air and reliable valve opening in water using current ramping rate of $0.1 \mathrm{~mA} / \mathrm{sec}$ was obtained. Further reduction in power consumption and optimization of valve performance is planned. Also, additional experiments will evaluate the performance of the valve in the presence of the radiotracer agent and in vivo.

\section{ACKNOWLEDGEMENTS}

This work was funded in part by the NIBIB (1 R01 NS050171). The authors would like to thank Dr. Donghai Zhu, Dr. Tuan Hoang, Mr. Neil Sardesai, and members of the Biomedical Microsystems Lab at University of Southern California.

\section{REFERENCES}

[1] D. P. Holschneider, J.-M. I. Maarek, J. Harimoto, J. Yang, and O. U. Sremin, "An Implantable Bolus Infusion Pump for Use in Freely Moving, Nontethered Rats," American Journal of Physiology, 283, H1713 (2002).

[2] D. P. Holschneider, J. Yang, Y. Guo, and J. M. I. Maarek, "Reorganization of functional brain maps after exercise training: Importance of cerebellar-thalamic-cortical pathway," Brain Research, 1184, 96-107 (2007).

[3] J. M. Maloney, S. A. Uhland, B. F. Polito, J. N. F. Sheppard, C. M. Pelta, and J. J. T. Santini, "Electrothermally activated microchips for implantable drug delivery and biosensing," Journal of Controlled Release, 109, 244 (2005).

[4] A. M. Cardenas-Valencia, J. Dlutowski, J. Bumgarner, C. Munoz, W. Wang, R. Popuri, and L. Langebrake, "Development of Various Designs of Low-Power MEMS Valves for Fluidic Applications," Sensors and Actuators A, 136, 374 (2007).

[5] J. Mueller, E.-H. Yang, A. Green, V. White, I. Chakraborty, and r. reinicke, "Design and Fabrication of MEMS-Based Micropropulsion Devices at JPL," Proceedings of SPIE, San Francisco, CA, 10/22/01 (2001), pp. 57-71.

[6] C.-C. Hong, J.-W. Choi, and C. H. Ahn, "Disposable Air-Bursting Detonators as an Alternative on-Chip Power Source," The 15th IEEE International Conference on Micro Electro Mechanical Systems, Las Vagas, NV, 1/20-24/02 (2002), pp. 240-243.

[7] L. J. Guerin, L. J. Guerin, O. Dubochet, J. F. Zeberli, P. A. C. P. Clot, and P. A. R. P. Renaud, "Miniature One-Shot Valve," The 11th IEEE International Conference on Micro Electro Mechanical Systems Heidelberg, Germany, 01/17-21/98 (1998), pp. 425-428.

[8] J. C. McDonald, S. J. Metallo, and G. M. Whitesides, "Fabircation of a Configurable, Single-Use Microfluidic Device," Analytical Chemistry, 73, 5645 (2001).

[9] D. W. Grattan and M. Bilz, "The Thermal Aging of Parylene and the Effect of Antioxidant," Studies in Conservation, 36, 44 (1991).

[10] T. von Karman, "Festigkeitsprobleme in Machinenbau," Encyklopadie der Mathematischen Wissenschaften, 4, 348 (1910). 